\title{
How to use thermal imaging in venous insufficiency?
}

\author{
Armand Cholewka ${ }^{1} \cdot$ Joanna Kajewska $^{1}$ Kawecki Marek $^{2} \cdot$ Karolina Sieroń-Stołtny $^{3}$. \\ Agata Stanek $^{4}$
}

Received: 23 August 2016/Accepted: 3 February 2017/Published online: 21 February 2017

(c) The Author(s) 2017. This article is published with open access at Springerlink.com

\begin{abstract}
This paper is intended to provide studies performed on usefulness of thermal imaging for the insufficiency of superficial veins in the lower limbs. The results are a continuation of the previous research and show a new way of analysis and better correlation between standard methods of parameters like duplex ultrasonography and parameters derived from thermal imaging. In particular promised seems to be using the mean whole limb temperature of healthy volunteers at a proper age as a threshold to count the isotherm area, and in isotherm analysis should be taken for the whole lower limb-the sum of thermal images from anterior and posterior views (Method II). The study was performed by the use of a Thermovision E60 camera by Flir Systems. All studies (duplex ultrasonography as well as thermal imaging) were performed in a research room with a stabilized temperature on two groups of patients, a group of healthy people and patients suffering from chronic venous disease. During the study, the correlation parameters were obtained with ultrasound and
\end{abstract}

Armand Cholewka

armand.cholewka@gmail.com

1 Department of Medical Physics, A. Chełkowski Institute of Physics, University of Silesia, Uniwersytecka 4, 40-007 Katowice, Poland

2 Burn Treatment Center Siemianowice Śląskie, Chair and Clinic of General Vascular and Transplanting Surgery, Silesian Medical University, Katowice, Poland

3 Department of Physical Medicine, Chair of Physiotherapy, School of Health Sciences in Katowice, Medical University of Silesia, Medyków Street 12, 40-752 Katowice, Poland

4 Department and Clinic of Internal Diseases, Angiology and Physical Medicine in Bytom, School of Medicine with the Division of Dentistry in Zabrze, Medical University of Silesia, Batorego Street 15, 41-902 Bytom, Poland thermal parameters. The results showed that temperature changes observed in the lower extremities of the thermal skin map are associated with a healthy state of blood supply which might be connected with blood stasis, inflammatory states and swelling that occurs in the soft tissues. We found the mean and higher correlations between thermal and ultrasound parameters, for example, a good positive correlation $(r=0.63)$ between the thermal range to the total limb length radio and the range of reflux was obtained. The correlation between thermal imaging parameters and duplex ultrasound parameters may show that thermovision is an extremely promising method, and it can be useful in the screening of diagnosis of superficial vein insufficiency.

Keywords Thermovision diagnostics - Temperature · Primary chronic venous disease · Duplex ultrasonography

\section{Introduction}

Chronic venous disease (CVD) is one of the most common diseases in the world. The disease is manifested, for example, by varicose veins, skin lesions and a more advanced form, including active venous ulcers. It is reported that even up to $50 \%$ of the population on earth may suffer from CVD [1, 2]. It happens that CVD is considered by patients as only a cosmetic defect, although it causes pain, discomfort and a decreased quality of life $[3,4]$. Therefore, this disease is both a medical and a social problem. Consequently, it is imperative to find a quick and noninvasive imaging method that can be useful in early diagnosis of in the problems related to the lower veins.

The standard technique used in diagnostic purposes for venous insufficiency is Duplex Ultrasound. In some cases, 
this method does not show the pathology of the venous system at the early stages of the disease, especially when the disease is associated with disorders relating to microcirculation. This is the limitation of ultrasound imaging. However, it is possible to use thermal imaging in diagnosis for pathological changes in the venous system in connection to the changes in that the temperature distribution is strictly connected with areas related to blood vessels tracts. We conclude that thermal imaging can explain local blood flow changes in the blood vessels, especially in the superficial layers of skin [5-11]. Such blood supply changes are connected with superficial lower extremities metabolism changes in tissue which may lead to the use of thermal imaging as a diagnostic tool in the early stages of chronic venous diseases [7, 12-14].

As mentioned, changes in blood flow located in the superficial layers of skin causes changes in skin temperature. These changes can be detected using thermography $[8,13,15-18]$.

There are several factors that can lead to diseases of the venous system in the lower extremities. The most important is the vein hypertension $[19,20]$. In most cases, venous hypertension results from the obstruction to venous flow, the dysfunction of venous valves, and/or failure of the "venous pump" [4, 19-26]. All of these factors cause pathology in the venous system which can be observed by the thermal imaging, because it is related to the change in temperature gradient of surface tissues [5, 7-9].

Nowadays, thermovision is used in many areas of medicine where a temperature map of the skin surface can give significant diagnostic information. Some examples of the branches of medicine that use thermal imaging are: dermatology, for foot ulcerations among patients with diabetes mellitus, breast thermography, and studies of inflammatory states and lower back pain diseases [5-17, 27, 28].

Another important aspect is the size of the pathologically changed soft tissue, which can be determined by thermal imaging. Thermal images show 3-5 times bigger areas characterized with a changed temperature gradient which can be easily seen by a physician [29-32]. This is related to the metabolism of the patient and with a high sensitivity infrared camera. As a result, the thermal method can be applied in the diagnosis of the skin, veins or diseases of soft tissues that are located in the superficial layer of the skin.

Currently, if physicians want to diagnose chronic venous disease, they use one of the following methods.

- The first one is duplex ultrasound. This method allows to estimate anatomy, venous flow as well as physiology and pathophysiology including the measurement of the duration of reflux $[3,4]$.
- The second one is the plethysmography-this noninvasive method allows one to estimate muscle work, venous reflux and venous outflow obstruction [33].

- The third method is liquid crystal thermography. This type of diagnostic test is not often used because it is difficult to perform [34].

- The last one is the thermovision, including the ease of performance, inexpensive and noninvasive diagnostic method, but not used as a standard technique yet [8].

Currently, thermal imaging is trying to be used as an example in the venous thrombosis of superficial veins [13]. It can give us an important information related to blood supply and metabolic changes of skin areas. It is apparent that this method can be useful, especially for the diagnosis of superficial vessels disorders.

Therefore, the aim of this study was to determine the usefulness of diagnostic thermal imaging in venous insufficiency and compare the thermal parameters with the parameters obtained from the duplex ultrasound.

\section{Materials and methods}

There were two independent groups of volunteers involved to the study. The research group that contained 38 cases (20 women and 18 male ages $60.3 \pm 11.0$ ) suffering from primary venous disease, and the control group consisting of 30 healthy people in a similar age as a research one (22 females and 8 males in age $50.0 \pm 18.9$ ). All volunteers have been subjected to a thermal examination of the lower limbs (in anterior and posterior projection).

The enrollment for the trial was performed in a group of patients with primary chronic disease stages $\mathrm{C} 2-\mathrm{C} 4$ who did not suffer from any other diseases, and in duplex ultrasonography reflux duration the only deviation that was found was $>500$ (ms) in the great saphenous vein (GSV). The results are a continuation and a completion of preliminary studies [13].

The research was completed at the Department and Clinic of Internal Diseases, Angiology and Physical Medicine, Medical University of Silesia in Bytom, Poland. All patients were examined by a angiologist before the study. They were requested not to smoke, drink alcohol or hot drinks for at least $3 \mathrm{~h}$ before the thermovision studies.

The thermal imaging of the lower extremities skin surface was performed by using a Thermovision Camera E60 camera by Flir Systems, Sweden. All patients were diagnosed by duplex ultrasonography (device Logic7) and the reflux duration, as well as the range of reflux, were determined.

The emissivity was set in the range of $0.97-0.98$. The thermal images of the chosen regions of interests (ROI) for both afflicted and healthy patients were performed in the 
same conditions by using the same protocol. The studies were performed in a special room where the temperature was stabilized $\left(23 \pm 1{ }^{\circ} \mathrm{C}\right)$. The distance between the camera and the body was about 1.3-1.5 m (depending on the size of the limb). It was necessary to follow the standard protocol of infrared imaging in medicine $[35,36]$.

All of the subjects signed a written consent for the diagnostics form, and they were previously informed about the plans and procedures.

The examination's protocol fulfills the ethical requirements of the 1975 Helsinki Declaration.

For the study, the following parameters were taken into account (Table 1):

- mean venous reflux duration (reflux duration), counted by duplex ultrasonography

- range of vein insufficiency (range of reflux), counted by duplex ultrasonography

- mean temperature derived from isotherms area $\left(T_{\text {mean,lesion }}\right)$, isotherms areas were marked using the mean temperature of the whole lower limb. The temperature above the mean limb temperature was taken as a temperature threshold used for the isotherms area in respective thermograms.

- mean temperature of lower extremity ( $T_{\text {mean }}$ of the whole limb), counted from thermograms

- range of isotherms' areas (thermal range), describes the range of increase in temperature along the limb

- temperature difference $\left(\Delta T=T_{\text {mean,lesion }}-T_{\text {mean }}\right)$

- ratio of whole lower extremity area and isotherm area (area \%).

The following methods of analysis defined the use of above parameters:

Method I Isotherm areas were marked on the lower extremities surface using the mean temperature of the whole lower limb (in practice it was the sum of the anterior area and posterior limb area). Any temperature higher than the mean limb temperature was understood as a temperature threshold and can be seen in the isotherm area in respective thermograms. Such isotherm areas may describe as pathologically changed tissues and point to inflammatory states or malfunctioning veins [36]. These areas were used to evaluate the percentage ratio between the isotherm and whole limb areas according to following formulas:

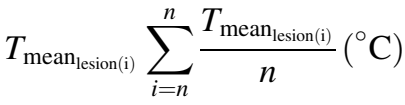

where $\Sigma$-sum $N$-Number of $\operatorname{cases} T_{\text {mean,lesion(i) }}$-the average temperature of the lesion for cases
$A=\frac{\text { AreaZ }}{\text { AreaK }} \times 100 \%$

where $A$-area [\%]Area $Z$ - the surface area of the affected tissue [pixel]Area $K$-surface area of the limb [pixel].

Method II Isotherm areas were marked on the whole lower extremities surface using the mean temperature of the lower limb from control group (in practice it was sum of anterior area and posterior limb area). The temperature higher than the mean limb temperature of control group was taken as a temperature threshold and made the isotherm area in respective thermograms. Such obtained areas were used to evaluate the percentage ratio between isotherm area and whole limb area but the threshold temperature was derived from the healthy people unlike to first method where it was equal to mean temperature of examined limb.

Method III This method was performed using ImageJ software. The idea of the third method was to evaluate the range of pathological changed veins by taken into consideration the whole limb. The range was considered as a region characterized with higher temperature than the mean limb temperature and was marked on the thermograms as a segment length.

Thermograms were analyzed by the use of a ThermaCAM TM Researcher Pro 2.8 SR-3. Statistical analyses were done in Statistica 10. Differences with a $p<0.05$ were regarded as significant.

\section{Results and discussion}

Skin temperature is an indicator of the heat exchange between internal tissues and the environment in which the organism is located. Resultant temperature map can show tissue metabolism changes as temperature gradient differentiation. It was discussed in previous paper presented preliminary results of thermal imaging in venous insufficiency. In this paper, the results was analyzed in a more comprehensive and a different way than it was done in preliminary studies [13].

There are thermograms of representative patient's limbs in anterior and posterior views presented in Figs. 1-3. Moreover, Figs. 2 and 3 present the thermograms after subtraction of areas characterized with lower temperature than isotherm threshold counted according to Methods I and II, respectively.

The areas characterized with higher temperature can be easily seen on the thermograms performed according to both methods of analysis. However, thermograms with isotherm areas marked on the lower extremities using the mean temperature of the whole lower limb of healthy volunteers seems to be different and a little bigger than 
Table 1 Temperature parameters [mean temperature derived from isotherm area $\left(T_{\text {mean,lesion }}\right)$, mean temperature of lower extremity $\left(T_{\text {mean }} o f\right.$ the whole limb), range of isotherm area (Thermal range to total whole limb ratio), temperature difference $\left(\Delta T=T_{\text {mean,lesion }}-T_{\text {mean }}\right)$, isotherm area to whole lower extremity area ratio (Area \%)] and duplex parameters [mean venous reflux duration (Duration of reflux), range of vein insufficiency (Range of reflux)] obtained for whole studied group of patients and healthy

\begin{tabular}{|c|c|c|c|c|c|c|c|c|c|c|}
\hline \multirow{2}{*}{$\begin{array}{l}\text { Number } \\
\text { of } \\
\text { patients }\end{array}$} & \multirow{2}{*}{$\begin{array}{l}\text { Duration } \\
\text { of reflux/s }\end{array}$} & \multirow{2}{*}{$\begin{array}{l}\text { Range } \\
\text { of } \\
\text { reflux }\end{array}$} & \multirow{2}{*}{$\begin{array}{l}T_{\text {mean }} \text { of the } \\
\text { whole limb } \\
(\text { Area } K) /{ }^{\circ} \mathrm{C}\end{array}$} & \multicolumn{3}{|l|}{ Method I } & \multicolumn{3}{|l|}{ Method II } & \multirow{2}{*}{$\begin{array}{l}\text { Method III } \\
\text { Thermal range (isotherm area) to } \\
\text { total whole limb length ratio }\end{array}$} \\
\hline & & & & $\begin{array}{l}T_{\text {mean,lesion }} \\
\left(\text { Area } Z \text { ) } /{ }^{\circ} \mathrm{C}\right.\end{array}$ & $\begin{array}{l}\Delta T / \\
{ }^{\circ} \mathrm{C}\end{array}$ & $\begin{array}{l}\text { Area/ } \\
\%\end{array}$ & $\begin{array}{l}T_{\text {mean,lesion }} \\
(\text { Area } Z) /{ }^{\circ} \mathrm{C}\end{array}$ & $\begin{array}{l}\Delta T / \\
{ }^{\circ} \mathrm{C}\end{array}$ & $\begin{array}{l}\text { Area/ } \\
\%\end{array}$ & \\
\hline 1 & 2 & 2 & 31.6 & 32.4 & 0.8 & 44 & 32.3 & 0.7 & 46 & 0.68 \\
\hline 2 & 2.5 & 2 & 30.0 & 30.9 & 0.9 & 47 & 32.2 & 2.2 & 13 & 0.65 \\
\hline 3 & 3 & 4 & 31.7 & 32.2 & 0.5 & 47 & 32.7 & 1.0 & 51 & 0.91 \\
\hline 4 & 3 & 2 & 31.0 & 32.2 & 1.2 & 50 & 32.1 & 1.1 & 34 & 0.75 \\
\hline 5 & 2.5 & 2 & 30.8 & 31.3 & 0.5 & 59 & 31.9 & 1.1 & 35 & 0.83 \\
\hline 6 & 0.5 & 3 & 30.5 & 31.1 & 0.6 & 53 & 32.1 & 1.6 & 19 & 0.83 \\
\hline 7 & 2 & 2 & 31.9 & 32.4 & 0.5 & 46 & 32.2 & 0.3 & 55 & 0.70 \\
\hline 8 & 2.5 & 3 & 31.3 & 32.0 & 0.7 & 50 & 32.2 & 0.9 & 42 & 0.84 \\
\hline 9 & 5 & 4 & 31.2 & 31.8 & 0.6 & 55 & 32.1 & 0.9 & 34 & 1.00 \\
\hline 10 & 3 & 3 & 30.9 & 31.8 & 0.9 & 39 & 32.4 & 1.5 & 29 & 1.00 \\
\hline 11 & 6 & 3 & 32.0 & 32.8 & 0.8 & 54 & 32.5 & 0.5 & 64 & 0.79 \\
\hline 12 & 3 & 4 & 32.9 & 33.6 & 0.7 & 51 & 32.7 & -0.2 & 74 & 0.80 \\
\hline 13 & 3 & 4 & 31.1 & 32.3 & 1.2 & 68 & 32.5 & 1.4 & 59 & 0.96 \\
\hline 14 & 2 & 4 & 31.1 & 32.5 & 1.4 & 55 & 32.4 & 1.3 & 52 & 0.94 \\
\hline 15 & 3 & 4 & 31.4 & 32.1 & 0.7 & 65 & 32.1 & 0.7 & 67 & 0.81 \\
\hline 16 & 2 & 4 & 31.1 & 31.8 & 0.7 & 76 & 31.9 & 0.8 & 62 & 0.98 \\
\hline 17 & 3 & 1 & 33.1 & 34 & 0.9 & 63 & 33.4 & 0.3 & 82 & 0.94 \\
\hline 18 & 3 & 1 & 31.4 & 32.2 & 0.8 & 57 & 32.1 & 0.7 & 64 & 0.78 \\
\hline 19 & 3 & 3 & 31.4 & 32.1 & 0.7 & 49 & 32.2 & 0.8 & 45 & 0.92 \\
\hline 20 & 3 & 3 & 31.3 & 32 & 0.7 & 58 & 32 & 0.7 & 58 & 0.89 \\
\hline 21 & 2 & 3 & 31.7 & 32.7 & 1 & 48 & 32.7 & 1.0 & 51 & 0.84 \\
\hline 22 & 2 & 3 & 31.2 & 31.8 & 0.6 & 67 & 31.9 & 0.7 & 59 & 0.85 \\
\hline 23 & 1 & 2 & 31.3 & 32 & 0.7 & 58 & 32 & 0.7 & 58 & 0.60 \\
\hline 24 & 7 & 3 & 31.5 & 32.2 & 0.7 & 66 & 32.2 & 0.7 & 66 & 0.83 \\
\hline 25 & 1 & 2 & 32.5 & 33.2 & 0.7 & 62 & 32.8 & 0.3 & 88 & 0.84 \\
\hline 26 & 7 & 3 & 32.4 & 33 & 0.6 & 69 & 32.9 & 0.5 & 89 & 0.96 \\
\hline 27 & 4 & 3 & 32.9 & 34.6 & 1.7 & 34 & 33.1 & 0.2 & 91 & 0.98 \\
\hline 28 & 4 & 3 & 32 & 32.7 & 0.7 & 53 & 32.5 & 0.5 & 72 & 0.96 \\
\hline 29 & 3 & 4 & 32.8 & 33.7 & 0.9 & 54 & 33 & 0.2 & 98 & 0.99 \\
\hline 30 & 3 & 4 & 32.4 & 33.1 & 0.7 & 69 & 32.9 & 0.5 & 88 & 0.98 \\
\hline 31 & 4 & 2 & 31.9 & 32.8 & 0.9 & 49 & 32.7 & 0.8 & 89 & 0.83 \\
\hline 32 & 4 & 2 & 31.7 & 33.2 & 1.5 & 39 & 32.8 & 1.1 & 57 & 0.65 \\
\hline 33 & 3 & 3 & 32.5 & 33.2 & 0.7 & 86 & 33.1 & 0.6 & 98 & 0.99 \\
\hline 34 & 3 & 3 & 32.7 & 33.2 & 0.5 & 63 & 32.9 & 0.2 & 92 & 0.83 \\
\hline 35 & 1 & 3 & 34.1 & 34.5 & 0.4 & 65 & 34.2 & 0.1 & 93 & 1.00 \\
\hline 36 & 1 & 3 & 34.2 & 34.7 & 0.5 & 79 & 34.4 & 0.2 & 1 & 1.00 \\
\hline 37 & 1 & 3 & 33.9 & 34.4 & 0.5 & 60 & 34 & 0.1 & 98 & 0.87 \\
\hline 38 & 1 & 3 & 34.3 & 34.9 & 0.6 & 56 & 34.5 & 0.2 & 95 & 0.98 \\
\hline \multicolumn{11}{|c|}{ Control group—healthy people } \\
\hline 1 & - & - & 31.1 & - & - & - & - & - & - & - \\
\hline 2 & - & - & 31.5 & - & - & - & - & - & - & - \\
\hline 3 & - & - & 32.4 & - & - & - & - & - & - & - \\
\hline 4 & - & - & 32.6 & - & - & - & - & - & - & - \\
\hline
\end{tabular}


Table 1 continued

\begin{tabular}{|c|c|c|c|c|c|c|c|c|c|c|}
\hline \multirow{2}{*}{$\begin{array}{l}\text { Number } \\
\text { of } \\
\text { patients }\end{array}$} & \multirow{2}{*}{$\begin{array}{l}\text { Duration } \\
\text { of reflux/s }\end{array}$} & \multirow{2}{*}{$\begin{array}{l}\text { Range } \\
\text { of } \\
\text { reflux }\end{array}$} & \multirow{2}{*}{$\begin{array}{l}T_{\text {mean }} \text { of the } \\
\text { whole limb } \\
(\text { Area } K) /{ }^{\circ} \mathrm{C}\end{array}$} & \multicolumn{3}{|l|}{ Method I } & \multicolumn{3}{|l|}{ Method II } & \multirow{2}{*}{$\begin{array}{l}\text { Method III } \\
\text { Thermal range (isotherm area) to } \\
\text { total whole limb length ratio }\end{array}$} \\
\hline & & & & $\begin{array}{l}T_{\text {mean,lesion }} \\
\left(\text { Area } Z \text { ) } /{ }^{\circ} \mathrm{C}\right.\end{array}$ & $\begin{array}{l}\Delta T / \\
{ }^{\circ} \mathrm{C}\end{array}$ & $\begin{array}{l}\text { Area/ } \\
\%\end{array}$ & $\begin{array}{l}T_{\text {mean,lesion }} \\
(\text { Area } Z) /{ }^{\circ} \mathrm{C}\end{array}$ & $\begin{array}{l}\Delta T / \\
{ }^{\circ} \mathrm{C}\end{array}$ & $\begin{array}{l}\text { Area/ } \\
\%\end{array}$ & \\
\hline 5 & - & - & 31.7 & - & - & - & - & - & - & - \\
\hline 6 & - & - & 31.8 & - & - & - & - & - & - & - \\
\hline 7 & - & - & 31.6 & - & - & - & - & - & - & - \\
\hline 8 & - & - & 31.6 & - & - & - & - & - & - & - \\
\hline 9 & - & - & 30.4 & - & - & - & - & - & - & - \\
\hline 10 & - & - & 30.5 & - & - & - & - & - & - & - \\
\hline 11 & - & - & 31.4 & - & - & - & - & - & - & - \\
\hline 12 & - & - & 31.6 & - & - & - & - & - & - & - \\
\hline 13 & - & - & 32.0 & - & - & - & - & - & - & - \\
\hline 14 & - & - & 31.7 & - & - & - & - & - & - & - \\
\hline 15 & - & - & 31 & - & - & - & - & - & - & - \\
\hline 16 & - & - & 32.2 & - & - & - & - & - & - & - \\
\hline 17 & - & - & 29.9 & - & - & - & - & - & - & - \\
\hline 18 & - & - & 30.2 & - & - & - & - & - & - & - \\
\hline 19 & - & - & 30.4 & - & - & - & - & - & - & - \\
\hline 20 & - & - & 30.7 & - & - & - & - & - & - & - \\
\hline 21 & - & - & 31.1 & - & - & - & - & - & - & - \\
\hline 22 & - & - & 31.1 & - & - & - & - & - & - & - \\
\hline 23 & - & - & 32.2 & - & - & - & - & - & - & - \\
\hline 24 & - & - & 32 & - & - & - & - & - & - & - \\
\hline 25 & - & - & 31.1 & - & - & - & - & - & - & - \\
\hline 26 & - & - & 31.6 & - & - & - & - & - & - & - \\
\hline 27 & - & - & 30.5 & - & - & - & - & - & - & - \\
\hline 28 & - & - & 30.7 & - & - & - & - & - & - & - \\
\hline 29 & - & - & 30.6 & - & - & - & - & - & - & - \\
\hline 30 & - & - & 30.9 & - & - & - & - & - & - & - \\
\hline
\end{tabular}

obtained according to Method I. One way or another the areas obtained by these two ways of analysis may describe the range of pathological changed veins and illustrate the range of inflammatory state occurred in soft tissues. The thermogram presented in Fig. 1 reveals prolonged areas localized mostly on the left tight ending in vicinity of the ankle in the anterior view and on both cruras in posterior view. Such thermal map may be correlated with the great saphena vein insufficiency and inflammatory state of soft tissue around it. It should be noted that areas marked according to Method II is bigger than obtained from Method I. It may indicate that during the performance of thermal imaging, only the parameters derived from the thermal images of healthy volunteers in standard conditions by using protocol should be administered [35, 36]. It seems that the suggested views may be enough in such a diagnosis, but the deeper analysis we present here will bring an answer.

All thermograms presented in Figs. 1-3 show elongated areas characterizing mainly the track of the vena saphena

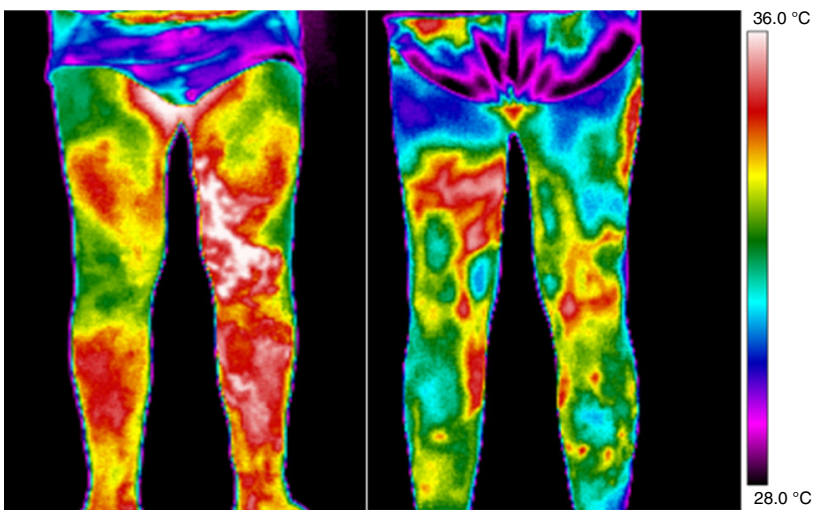

Fig. 1 Thermograms of representative patient's limbs in anterior and posterior position

magna vein and vena saphena parva. These areas are clearly seen in both views and can be connected with pathological changes in the veins. Thus, the thermograms may bring undoubtedly qualitative information for 


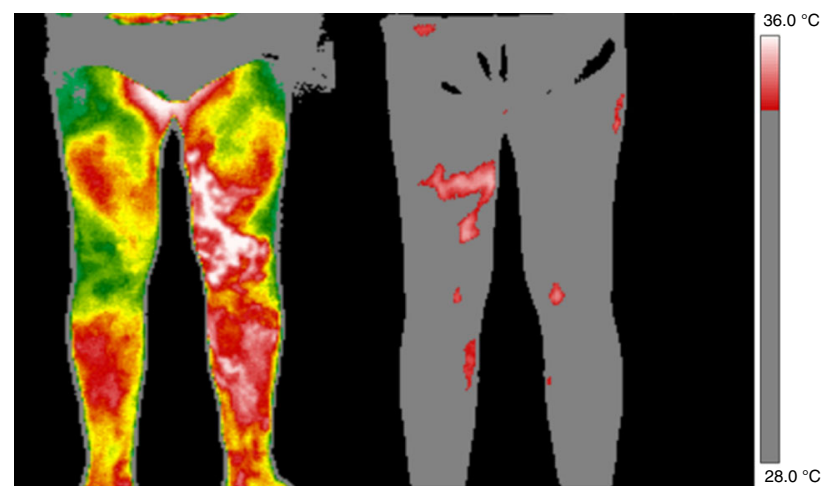

Fig. 2 Thermograms from Fig. 1 after subtraction of areas characterized with lower temperature than isotherm counted according to Method I

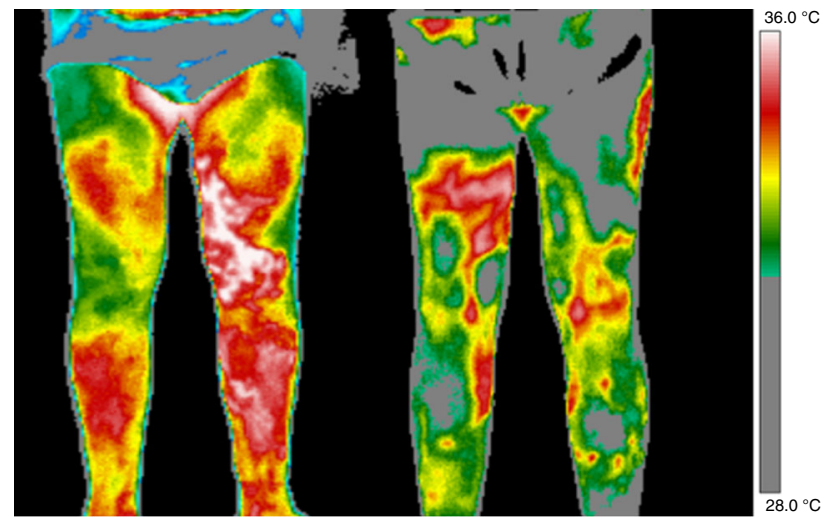

Fig. 3 Thermograms from Fig. 1 after subtraction of areas characterized with lower temperature than isotherm counted according to Method II

angiologists. Yet increased temperature manifested in the superficial vein track may be associated with some functional problems of venous valves due to, for example, blood stasis. It may lead to other pathological vein changes like vein deformation that is visible on the skin surface, as areas with higher temperatures, unlike the healthy lower limbs we discussed in the previous work [13]. There are some processes that play main roles in venous insufficiency including leukocyte entrapment, hyperviscosity of blood and fibrin cuff. All of these may have an influence on soft tissue metabolism and skin temperature gradient. Furthermore, the number of morphotic elements in blood influences the blood flow in capillaries because of their influence on viscosity. But the important thing is also the interaction of morphotic blood elements with endothelium cells. The friction has an influence on the temperature inside the vessels as well as in surrounding soft tissues due to the leukocytosis influence which leads to increase in resistance and blood pressure. Additionally, the erythrocytes are smaller than white blood cells so they flow faster and can lead to an aggregation of erythrocytes and push white blood cells to the vessel walls. This is called the leukocytes-erythrocytes train. It leads to a process of leukocytes rolling and adhering to endothelium cells causing the leukocyte entrapment. Such processes lead to damage in endothelium and lead to a migration of leukocytes through the blood vessel walls $[13,15,16]$. And, as a result of the release of cytotoxic substances and the changes in blood cells, the vessel walls can be damaged, which enables the increase in permeability and the beginning of an inflammatory state. It is easy to see the results of these processes in thermal imaging because they lead to temperature gradient changes located mostly on the route of the chosen vein. The very important factor is that these processes take place in small vessels so they are strictly connected with microcirculation and cannot be visible in duplex ultrasonography. These processes have an impact on metabolism and temperature, which is reflected on the skin can be easily detected by thermovision.

Untreated vein insufficiency or very late diagnosis leads to swelling, which occurs in the soft tissue of the limbs and causes an increase in blood pressure, a narrowing of capillaries and a decrease in blood flow. Such effects may lead to ischemia and oxygen deficiency in tissues and consequently to venous ulcers which we reported in previous papers $[8,9]$. This is also manifested by changes in temperature gradient, mostly a decrease in temperature in soft tissues due to slow thermoregulation. Such skin temperature effects should not be visible in healthy limbs.

Despite of mean temperature of the limb or isotherm area, it could be interesting if the range of reflux may be correlated with the thermal range along the limb (described as the ratio of range of area characterized by a higher temperature than the healthy mean limb temperature to whole limb length, and as was marked on the thermograms as a segment length). The result of this method of analysis is presented in Fig. 4. One can see on all thermograms that the counted ratio differ between the limbs and probably it has something to do with the reflux range because of a higher temperature appearing along the superficial vein track.

It may seem that the differences in temperature gradient can be easy correlated with the medical diagnosis and that is why it was interesting to check the correlation between temperature and area parameters with duplex ultrasonography parameters.

To see the problem more clearly, the correlation between the duplex ultrasonography parameters (range of reflux and duration of reflux) and the temperature parameters, (mean temperature derived from isotherm area ( $\left.T_{\text {mean,lesion }}\right)$, mean temperature of whole limb, thermal range of isotherm area to total limb length ratio, ratio of 


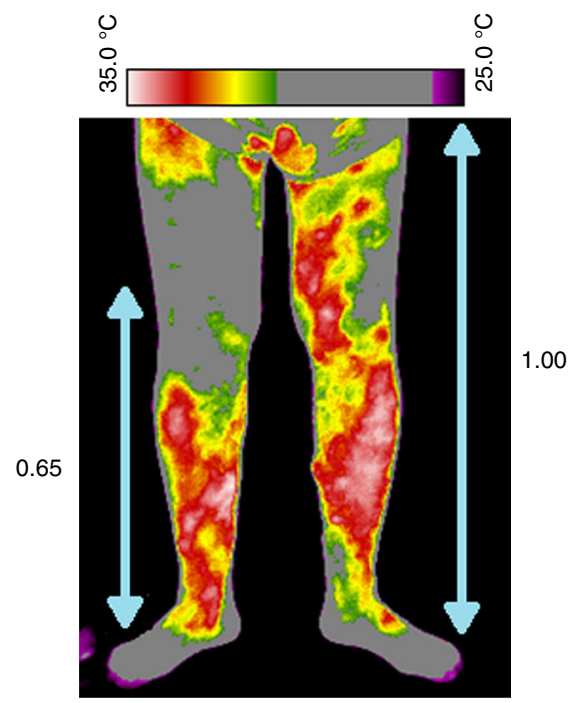

Fig. 4 Representative thermograms with marked lines described the isotherm area length to whole limb length ratio calculated according to Method III

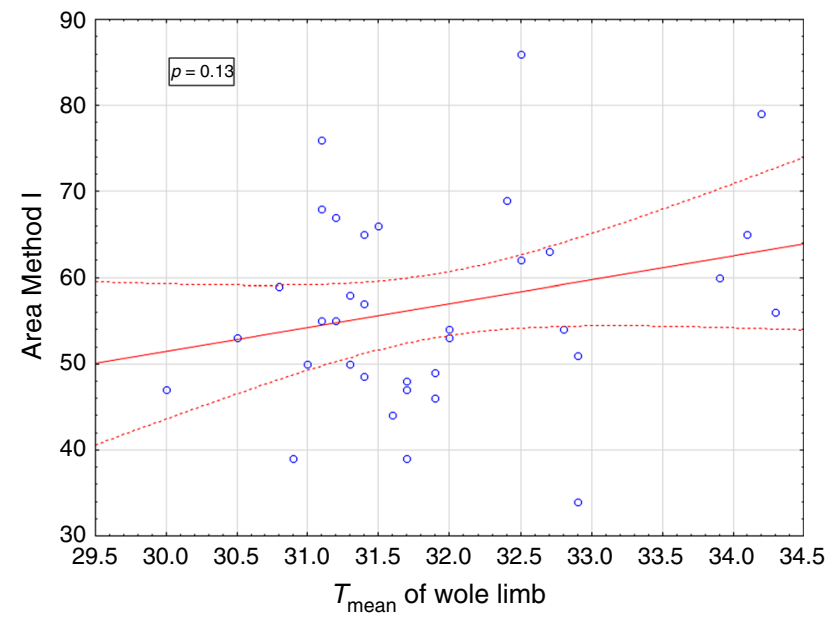

Fig. 5 Correlation between mean temperature of whole limb (anterior and posterior position) and isotherm area (Area \%) obtained for all patients, where $\boldsymbol{r}$ is the correlation coefficient, calculated according to Method I

whole lower extremity area and isotherm area (Area \%), the correlations were performed and presented in Figs. 5-9.

It can be seen from Fig. 5 that there is no statistically significant correlation between the mean temperature of the whole limb and isotherm area $(p=0.13)$ for thermal parameters calculated according to Method I. However, a similar correlation for parameters calculated according to Method II is the mean and positive $(r=0.86)$ what can be easily seen in Fig. 6 . This may seem that the areas obtained after subtraction of the areas characterized with lower temperature than the isotherm calculated according to Method II are much different than according to Method I

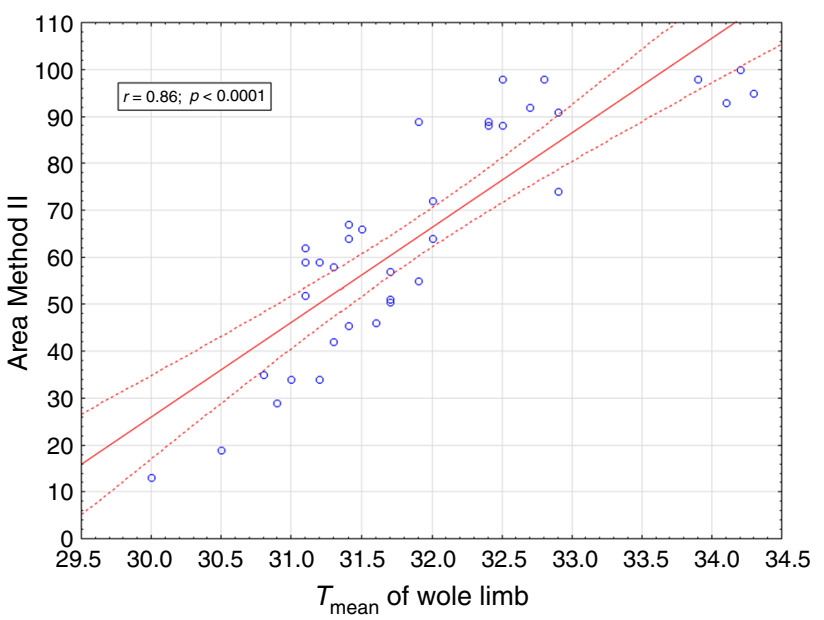

Fig. 6 Correlation between mean temperature of whole limb (anterior and posterior position) and isotherm area (Area \%) obtained for all patients, where $\boldsymbol{r}$ is the correlation coefficient, calculated according to Method II

and can be also clearly seen in Figs. 2 and 3. So it could be good advice that in regular thermovision diagnosis of venous insufficiency the mean limb temperature of healthy volunteers at a proper age should be taken as a threshold to count the isotherm area (Fig. 7).

The other statistically significant result was a high negative correlation $(r=-0.82)$ between the isotherm area (Area \%) and $\Delta T$, calculated according to Method II. Such a result means that the mean temperature of the whole limb is strictly connected with the mean temperature of the isotherm area (mean temperature of lesion).

It seems to be obvious because a bigger isotherm area determines the temperature of the limb. It should be noted that the isotherm area is a result of increased limb skin temperature due to the improper functioning of vein valves,

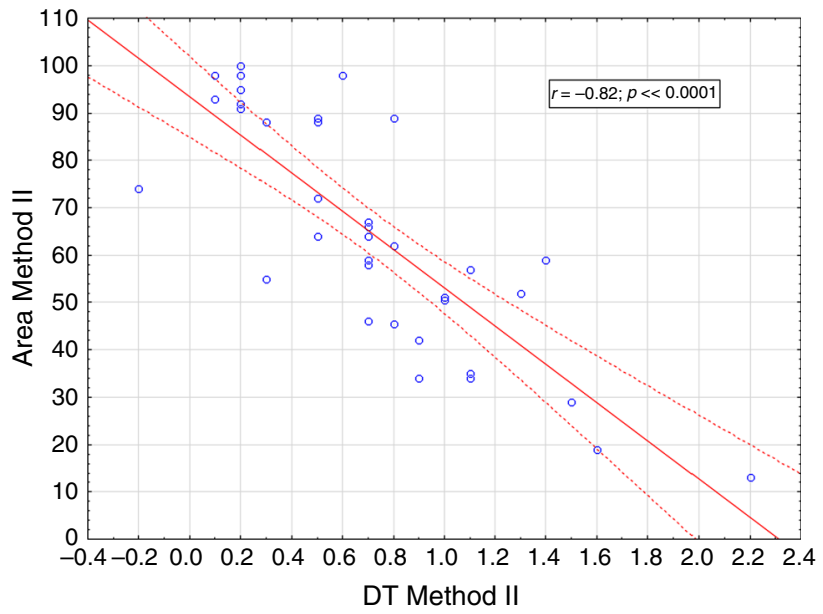

Fig. 7 Correlation between isotherm area (Area \%) and $\Delta T$, calculated according to Method II, obtained from all patients, where $\boldsymbol{r}$ is the correlation coefficient 
and the release of different cytotoxic substances leading to damage in the vessel walls, which enables the increase in permeability and the beginning of an inflammatory state. Such processes lead to a widening of skin area indicated by a higher temperature, which has an influence on the decrease in temperature difference between the whole limb and the isotherm area, simultaneously increasing the Area \%. Similar processes provide a correlation between the mean temperature of the lesion calculated according to Method II, and the thermal range to total limb length ratio, presented in Fig. 8. The correlation coefficient indicated a mean positive correlation with $r=0.42$. It also may point out that in thermal diagnosis the mean limb temperature of healthy people in the proper age should be taken in comparison.

The other parameter evaluated by ultrasound imaging is range of vein insufficiency. So the next question was if it is possible to evaluate the range of vein insufficiency (Range of reflux), by using the thermal imaging. The first attempt of this problem has been discussed in literature [13], but the correlation was not successful. For this reason, in this study the number of patients is much bigger and the thermal range was also calculated according to Method II. The result is presented in Fig. 9, where we can see that there is a much bigger correlation $(r=0.63)$ than in previous work $(r=0.46$ [13]) between the thermal range to total limb length radio and range of reflux. It follows that this way of analysis may be right, owing to a better and statistically significant correlation between the thermal range, defined as the thermal range to total limb ratio (described as a range of increased temperature along the limb), and the range of great saphenous vein insufficiency calculated by duplex ultrasonography.

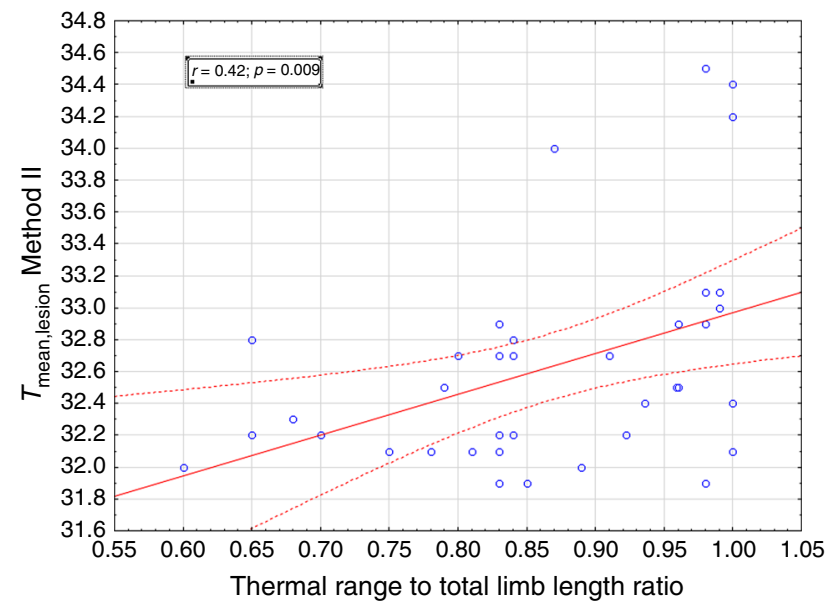

Fig. 8 Correlation between mean temperature of the lesion (isotherm area), calculated according to Method II, and thermal range to total limb length ratio, obtained from all patients, where $\boldsymbol{r}$ is the correlation coefficient

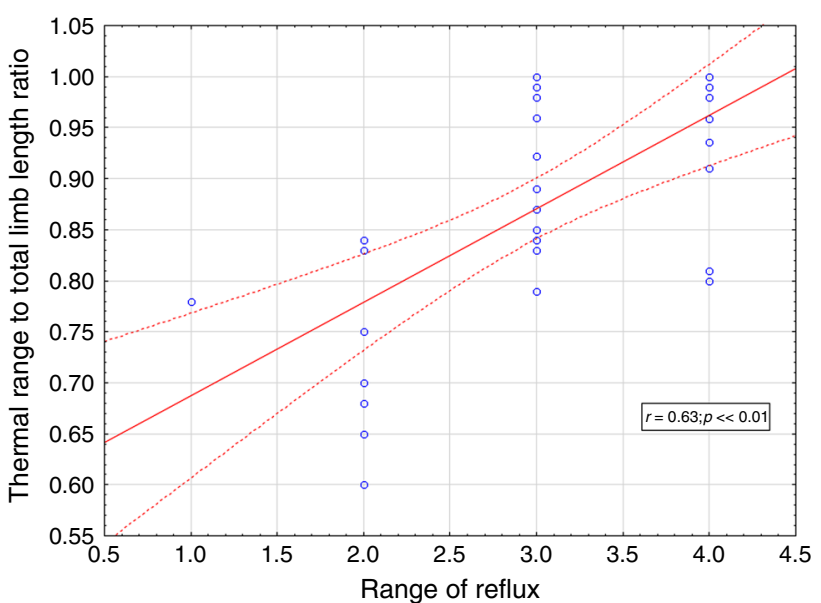

Fig. 9 Correlation between the thermal range to total limb length radio and range of reflux obtained from all patients, where $r$ is the correlation coefficient

Possibly a better correlation will be found when the study group is bigger. Nevertheless, even on the level of the research presented, it can be observed that the totally noninvasive imaging technique, thermovision, is useful in the diagnosis of venous insufficiency. Thermovision provides a faster, cheaper and easier method to use, at minimum in screening or for first contact with a physician, just to determine if there are some temperature gradient changes which might be connected with blood supply disorders. It is possible to see not only big venous malfunction like vena saphena magna, but at first the microcirculation problems that are impossible to see in ultrasound imaging.

Thermal imaging as a diagnostic method in superficial vein diseases is promising and should be developed. The qualitative and quantitative results show that changes to the thermal limb map and mean temperature correlates with physiological diseases processes developing and occurring in capillaries, and the tissues that could not be seen in duplex scanning. It is very important to evaluate the standard protocol for using thermovision for vein insufficiency diseases and our studies offer some potential solutions.

\section{Conclusions}

The results are a continuation of long-term studies developed by our research group.

As an innovation, the isotherm areas were marked on the whole lower extremities surface using the mean temperature of the lower limb from the control group (in practice it was the sum of the anterior and posterior limb areas). Such a change caused that a statistically significant high positive correlation $(p=0.86)$ between the mean temperature of the whole limb and isotherm area was obtained. 
Additionally, we found a much bigger correlation ( $r=0.63)$ than in previous work $(r=0.46$ [13]) between the thermal range to total limb length radio and range of reflux.

It is apparent that in thermovision imaging of lower extremities venous disorders, the mean whole limb temperature of healthy volunteers at a proper age should be taken as a threshold to count the isotherm area, and in isotherm analysis should be taken for the whole lower limb; for simplification it can be taken as the sum of thermal images from anterior and posterior views.

The correlation obtained shows that thermovision is promising and may be used in the diagnosis of superficial vein insufficiency.

Finally, a bigger population of afflicted and healthy patients improved the correlations found in an earlier paper and shows that the chosen method of study may be appropriate.

Open Access This article is distributed under the terms of the Creative Commons Attribution 4.0 International License (http://creative commons.org/licenses/by/4.0/), which permits unrestricted use, distribution, and reproduction in any medium, provided you give appropriate credit to the original author(s) and the source, provide a link to the Creative Commons license, and indicate if changes were made.

\section{References}

1. Van den Oever R, Hepp B, Debbaut B, Simon I. Socio-economic impact of chronic venous insufficiency. An underestimated public health problem. Int Angiol. 1998;17:161-7.

2. Kaplan RM, Criqui MH, Denenberg JO, Bergan J, Fronek A. Quality of life in patients with chronic venous disease: San Diego population study. J Vasc Surg. 2003;37:1047-53.

3. Gloviczki P, Comerota AJ, Dalsing MC, Eklof BG, Gillespie DL, et al. The care of patients with varicose veins and associated chronic venous diseases: clinical practice guidelines of the society for vascular surgery and the american venous forum. $\mathrm{J}$ Vasc Surg. 2011;53(5Suppl):1S-48S.

4. Sieroń A, Cierpka L, Rybak Z, Stanek A. Angiology texbook. Bielsko Biała: Alfa Medica Press; 2009.

5. Cholewka A, Drzazga Z, Sieroń A, Stanek A. Thermovision diagnostics in chosen spine diseases treated by whole-body cryotherapy. J Therm Anal Calorim. 2010;102:113-9.

6. Cholewka A. Diagnostic meaning of thermographic analysis of whole body cooling in cryotherapy. In: Skrzek A, Podbielska H, editors. Applications of low temperature in medicine. Warszawa: OWPW; 2012 (in Polish).

7. Cholewka A, Stanek A, Kwiatek S, Sieroń S, Drzazga Z. Does the temperature gradient correlate with photodynamic diagnosis parameter NCV? Photodiagn Photodyn Ther. 2013;10:33-8.

8. Cholewka A, Drzazga Z, Sieroń A, Stanek A, Knefel G, et al. Some applications of thermal imaging in medicine. In: Drzazga $\mathrm{Z}$, Ślosarek K, editors. Some aspects of medical physics-in vivo and in vitro studies. Polish Journal of Environmental Studies; 2010. p. 51-8.

9. Cholewka A, Knefel G, Stanek A, Kawecki M, Ml N, et al. Thermal imaging and TC oximetry measurements of hyperbaric oxygen therapy (HBO) effects on trophic ulceration of the crura. J Therm Anal Calorim. 2012;108:25-31.
10. Cholewka A, Drzazga Z, Knefel G, Kawecki M, Nowak M. Thermal imaging in hyperbaric oxygen therapy (HBO). Inżynieria Biomedyczna.

11. Ammer K. Temperature effects of thermotherapy determined by infrared measurements. Physica Medica. 2004;20 Suppl I:64-6.

12. Cholewka A, Drzazga Z, Michnik A, Sieroń A, Wiśniowska B. Temperature effects of whole cryotherapy determined by termography. Thermol Int. 2004;14:57-63.

13. Cholewka A, Stanek A, Klimas A, Sieroń A, Drzazga A. Thermal imaging application in chronic venous disease: pilot study. J Therm Anal Calorim. 2013; doi:10.1007/s10973-013-3356-0.

14. Mercer JB, Ring EFJ. Fever screening and infrared thermal imaging: concerns and guidelines. Thermol Int. 2009;19:67-9.

15. Bauer J, Hurnik P, Zdziarski J, Mielczarek W, Podbielska H. Thermovision and its applications in medicine. Acta Bio Opt Inf Med. 1997;3(2-4):121-31.

16. Bauer J, Hurnik P, Zdziarski J, Mielczarek W, Skrzek A, Podbielska H, Zagrobelny Z. Thermovison evaluation of cryotherapy effects. Acta Bio Opt Inf Med. 1997;3(2-4):133-40.

17. Nowakowski A, editor. Thermography progresses-medical applications. Gdańskie: Wydawnictwo; 2001.

18. Boerner E, Bauer J, Ratajczak B, Dereń E, Podbielska H. Application of thermovision for analysis of superficial temperature distribution changes after physiotherapy-comparison of infrared irradiation and cryotherapy. J Thermal Anal Calorim. 2015;120(1):261-7. doi:10.1007/s10973-014-4026-6.

19. Wilkinson LS, Bunker C, Edwards JC, Scurr JH, Smith PD. Leukocytes: their role in the etiopathogenesis of skin damage in venous disease. J Vasc Surg. 1993;17(4):669-75.

20. Hess CT. Identifying and managing venous dermatitis. Adv Skin Wound Care. 2005;18(5 Pt 1):242-3.

21. Bollinger A, Isenring G, Franzeck UK. Lymphatic microangiopathy: a complication of severe chronic venous incompetence (CVI). Lymphology. 1982;15(2):60-5.

22. Bollinger A, Leu AJ, Hoffmann U, Franzeck UK. Microvascular changes in venous disease: an update. Angiology. 1997;48(1): $27-32$.

23. Bradbury AW, Murie JA, Ruckley CV. Role of leucocyte in the pathogenesis of vascular disease. Br J Surg. 1993;80(12): 1503-12.

24. Einspahr JG, Thomas TL, Saboda K, Nickolof BJ, Jl W, et al. Expression of vascular endothelial growth factor in early cutaneous melanocytic lesion progression. Cancer. 2007;110(11):2519-27.

25. Shor NA, Pronin IV. Local signs of the reperfusion syndrome in obliterating atherosclerosis of the lower extremity arteries and their treatment. Klin Khir. 2006;1:34-7.

26. Sukovatykh BS, Kniazev VV. The mechanisms of critical impairments of microcirculation in patients with chronic ischemia of lower extremities. Vestn Khir Im II Grek. 2007;166(4): $20-4$.

27. Ammer K. Temperature effects of thermotherapy determined by infrared measurements. Phys Med. 2004;20(Suppl. I):64-6.

28. Ring EFJ. Provocation tests in thermal imaging, Abs. Thermol Int. 2001;11(2):5459.

29. de Weck AL, Gluck U, Derer T. Thermografic analysis of allergic reactions in the skin. J Allergy Clin Immunol News. 1990;2:7-10.

30. de Weck AL, Gluck U, Bahre M. Investigation of the anti-allergic activity of azelastine on the immediate and late phase reactions to allergens and histamine using telethermography. Clin Exp Allergy. 2000;30:283-7.

31. Siebennaar F, Degener F, Zuberbier T, Martus P, Maurer M. High-dose desloratadine decreases wheel volume and improves cold provocation thresholds compared with standard-dose treatment in patients with acquired cold urticaria: a randomized, placebo-controlled, crossover study. J Allergy Clin Immunol. 2009;123:672-9. 
32. Rok T. The use of thermovision in diagnostics and therapy. 2012. Doctor thesis, Jagiellonian Univeristy Kraków.

33. Nicolaides AN, Cardiovascular Disease Educational and Research Trust, European Society of Vascular Surgery, The International Angiology Scientific Activity Congress Organization, International Union of Angiology, Union Internationale de Phlebologie at the Abbaye des Vaux de Cernay. Investigation of chronic venous insufficiency: a consensus statement (France, March 5-9, 1997). Circulation. 2000;129:126-63.
34. Cameron EW, Sachdev D, Gishen P, Martin JF. Liquid crystal thermography as a screening test for deep vein thrombosis in patients with cerebral infarction. Eur J Clin Invest. 1991;21(5):548-50.

35. Ammer K. The Glamorgan Protocol for recording and evaluation of thermal images of the human body. Thermol Int. 2008;18(4):125-9.

36. Ring EFJ, Ammer K. The technique of infrared imaging in medicine. Thermol Int. 2000;10(1):7-14. 